\section{Edycaçäa

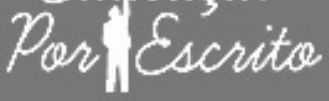

ARTIGO

\section{Editor}

Maria Inês Côrte Vitoria PUCRS, RS, Brasil

\section{Equipe Editorial}

Pricila Kohls dos Santos PUCRS, RS, Brasil

Marcelo Oliveira da Silva PUCRS, RS, Brasil

Carla Spagnolo

PUCRS, RS, Brasil

Rosa Maria Rigo

PUCRS, RS, Brasil

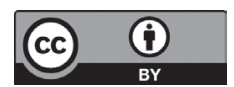

A matéria publicada neste periódico é licenciada sob forma de uma Licença Creative Commons - Atribuição 4.0 Internacional. http://creativecommons. org/licenses/by/4.0/

\title{
Egressos do ensino superior das instituições de ensino privadas de São Mateus, ES: competências necessárias para o mercado de trabalho
}

\author{
Graduates of Higher Education Institutions of private education Matthew, ES:
} skills needed for the labor market

\section{Maria Nilda Bissaro ${ }^{a}$ Marcus Antonius da Costa Nunes ${ }^{b}$}

RESUMO: O século XXI, fortemente marcado pelas mudanças sociais, econômicas e tecnológicas, exige mudanças no perfil do trabalhador em relação à qualificação da sua força de trabalho. Neste sentido, o propósito deste estudo é investigar o que pensa o jovem egresso de 2013 das Instituições de Ensino Privadas de São Mateus sobre sua preparação para o mercado de trabalho e, investigar o que este mercado exige em termos de qualificação profissional. Levando em consideração este contexto, a questão a ser discutida é o quanto este jovem se sente preparado para o mercado de trabalho e, o que este mercado exige em termos de qualificação profissional. Objetiva-se verificar se há alinhamento entre as competências dos formandos com as demandadas pelo mercado de trabalho local. A investigação, realizada através de duas pesquisas paralelas, a primeira junto ao público acadêmico e a segunda junto ao público corporativo, identifica que existem fragilidades tanto por parte da capacitação formal quanto pela falta de qualificação da mão de obra colocada no mercado.

Palavras-chave: Formação Acadêmica. Qualificação. Mercado de Trabalho.

ABSTRACT: The XXI Century, strongly marked by social, economic and technological change requires changes in the profile of workers in relation to the qualification of its workforce. In this sense, the purpose of this study is to investigate what egress think the young 2013 Private Education Institutions of Matthew about his preparation for the labor market, and investigate what this market demands in terms of professional qualification. Taking into account this context, the question to be discussed is how this young man feels prepared for the job market

\footnotetext{
a Mestrado (2014) em Gestão Social, Educação e Desenvolvimento Regional, linha de pesquisa em educação, pela Faculdade Vale do Cricaré (FVC) de São Mateus - ES. Graduação em Turismo (2005), especialização em Docência do Ensino Superior (2007) e Graduações em História e Geografia (2008) pela FVC. Professora das disciplinas Sociologia, Antropologia, Arte e Cultura, Ética e Responsabilidade Social e Práticas em Geografia nos cursos de Pedagogia, Com. Social, Contábeis e Administração da FVC. Brasil. <nilbissaro@terra.com.br>.

b Orientador, Doutor Professor e Coordenador do Mestrado Profissional em Gestão Social, Educação e Desenvolvimento
} Regional.<munivc@gmail.com>. 
and what the market demands in terms of professional qualification. The objective is to check for alignment between the skills of graduates with the defendants by the local labor market. The research, carried out through two parallel studies, the first by the academic audience and the second with the corporate audience, identifies weaknesses that exist both within the formal training as the lack of qualification of the labor force on the market.

Keywords: Academic Training. Qualification. Labor Market.

E ssa pesquisa, inspirada na rotina profissional da autora deste trabalho, nasceu da necessidade de se esclarecer as prováveis dificuldades que as pessoas demonstram ao procurar emprego e, as dificuldades encontradas pelo mercado ao recrutar pessoas para assumir os mais diversificados postos de trabalho, de modo que, foram pesquisados os egressos do ano de 2013/2 das IES - Instituição de Ensino Superior particulares de São Mateus, ES, com foco na percepção dos egressos acerca da qualidade do aprendizado e, daquilo que pensam os gestores de algumas empresas de relevância na contratação da mão de obra local, com foco nas exigências sobre qualificação profissional.

O final do século XX e nessa primeira década do Século XXI foram fortemente marcados pela mudança no perfil do trabalhador exigido pelo mercado de trabalho. Drucker (2001), um dos pioneiros em vislumbrar essa necessidade, diz que o principal recurso é o conhecimento. Tornar o trabalho produtivo e transformar o trabalhador em realizador é o desafio que as empresas enfrentam diariamente. Para tanto, as empresas só precisam de um único recurso: o homem. Torná-lo produtivo. Essa é a função essencial das organizações. Diante desse desafio é necessário que se saiba administrar os trabalhadores para se obter o máximo de produtividade. Isso requer um recrutamento cuidadoso com aprendizado e ensinamentos contínuos. Nesse sentido Drucker (2001) aconselha que se deva considerar, no processo seletivo, certo número de pessoas potencialmente qualificadas e, para se tomar uma decisão eficiente, o executivo deve considerar de três a cinco candidatos qualificados, tarefa esta, bastante difícil de ser cumprida.

As pesquisas mostradas pelo Relatório da Firjan (2012) apontam a falta de mão de obra qualificada no mercado de trabalho e, apontam também a dificuldade que as empresas têm para preencher uma vaga em aberto, conforme Catho (2012) os pré-requisitos são claros em seus anúncios: exige-se que o candidato tenha, no mínimo, o ensino médio completo e estamos num momento em que, dependendo do porte da empresa, não se contrata mais sem o nível superior. O Relatório Firjan (2012, p. 23) comprova que as exigências em termos de formação dos profissionais são altas, portanto para os trabalhadores de nível básico será muito difícil empregar-se sem ter o nível médio. O nível superior será um diferencial de grande relevância.

Por sua vez, o relatório produzido pelo Inep - Instituto Nacional de Ensino e Pesquisas Educacionais (2012), relata que entre os anos de 2001 a 2012 a oferta de número de cursos superiores aumentou consideravelmente: saltou 
de 1.235 em 2001 para 2.756 em 2012. No entanto há que se considerar também a grande diferença entre o número de alunos matriculados e alunos concluintes: alunos matriculados 7.058 .000 e alunos concluintes 1.056 .000 , indicando claramente uma grande evasão.

A carência de mão de obra qualificada aflige sete em cada dez empresas brasileira. Sondagem Especial (2011) afirma que, além desse número, outro dado que contribui para que o cenário da empregabilidade continue a perdurar negativamente: o receio que os empresários têm em treinar seus funcionários e depois perdê-los para a concorrência, como revelaram $38 \%$ das 1.616 empresas consultadas. O percentual sobe para $46 \%$ se o foco for apenas as grandes companhias.

Por esse motivo, a pesquisa revelou que as empresas em geral investem na retenção de talentos, segunda ação mais usada (a primeira é o treinamento), para enfrentar a falta de pessoal qualificado. Fonseca $(2011$, p. 8) afirma que "É preciso agir imediatamente porque esse é um problema que leva gerações para resolver".

Portanto, o objetivo da pesquisa foi o de entender a percepção dos egressos 2013 das IES do ensino privado em São Mateus, ES, sobre suas habilidades e competências para o mercado de trabalho, considerando duas linhas de ação: a primeira diz respeito ao que pensa o jovem egresso 2013 sobre sua capacitação e a segunda, sobre o que pensam os especialistas da área de Recrutamento e Seleção sobre a qualidade dessa mão de obra. Então, a problemática é: esses jovens estão aptos para assumir postos de trabalho no mercado local?

O aprendizado tem que ser relevante para as qualificações necessárias ao sucesso na economia do conhecimento, pois conforme já citado, com base em Fonseca (2011, p. 8), [...] o trabalhador com uma base educacional fraca apresenta maior dificuldade para aprender processos [...]. A educação não mais termina quando o aluno se forma na escola tradicional; espera-se que os trabalhadores construam sua base de conhecimento ao longo da vida.

A falta de mão de obra qualificada deixou de ser uma preocupação isolada de alguns setores [...] mesmo quem resolve assumir a qualificação dos empregados esbarra em outra dificuldade ainda mais séria, que é a deficiência na educação básica dos trabalhadores [...] as companhias têm receio em treinar o funcionário e depois perdê-lo para a concorrência. (INFORMATIVO RANDON, 2011, p. 8)

Nesse contexto, as IES de São Mateus, ES, têm papel fundamental no desenvolvimento dessa mão de obra, pois, são as Instituições que surgem como uma das fontes de suporte à construção de cidades desenvolvidas (FLECK, 2011). Santos (2008, p.68) diz que "O setor terciário "evoluído" é privilégio de pessoas educadas e, se possível, diplomadas. Sua evolução máxima coincide, em longo prazo, com o crescimento da taxa de escolaridade urbana". 
Essa pesquisa procurou investigar os egressos 2013 de duas Instituições de Ensino Superior Privadas em São Mateus, ES, objetivando o alinhamento entre o que a educação oferece e o que o mercado demanda, para tanto, 242 alunos formandos 2013 foram pesquisados, sendo que, desses, considerou-se uma amostragem de $64 \%$ aplicando-se o questionário a 154 alunos dos diversos cursos oferecidos pelas IES privadas. Utilizou o método quantitativo para a abordagem educacional com 14 perguntas fechadas e o método qualitativo para a pesquisa corporativa, tendo em vista que os dados coletados dessa pesquisa resultam de três perguntas abertas cujas respostas foram agrupadas por padrão, dada a subjetividade do assunto.

\section{A educação na sociedade contemporânea}

Galleguillos e Catani (2011), apud Oliveira (2000), abordam as modificações ocorridas na sociedade contemporânea, onde a educação adquire nova função social, seja pelas modificações na qualificação da força de trabalho, seja pela diminuição dos Estados nacionais. No Brasil, a reforma do Estado tornou-se tema central em 1995, no governo de Fernando Henrique Cardoso. Para o então ministro Bresser-Pereira, o aumento da eficiência da administração pública necessitava de um projeto de reforma que, concomitantemente, criaria um núcleo estratégico do Estado. Diante desse cenário, muitas mudanças foram propostas, entre elas a reestruturação do Ensino Superior implantado a avaliação e a autonomia das IES.

Galleguillos e Catani (2011) discutem o papel do sistema de avaliação da educação superior no Brasil justificando que foi a desqualificação dos serviços públicos e a necessidade de sua substituição pelo mercado privado e individual, que aumentou a eficiência e agilidade na gestão dos serviços, principalmente daqueles considerados não exclusivos do Estado, dentre estes, as universidades.

[...] o Estado reduz seu papel de executor ou prestador direto de serviços, mantendo-se, entretanto, no papel de regulador e provedor ou promotor destes, principalmente dos serviços sociais como educação e saúde [...]. (BRASIL, 1995, p. 13)

Assim, Galleguillos e Catani (2011) afirmam que diante da nova concepção de Estado, a proposta, no âmbito do Ministério da Educação e Cultura, passa a ser uma profunda reestruturação da educação superior, considerada necessária diante da incapacidade do sistema federal de ensino superior em absorver a crescente demanda, formar para o mercado e manter o modelo de universidade de pesquisa. 
Desse modo, Galleguillos e Catani (2011), mostram que esse novo desenho das atuais políticas públicas, próprio das práticas de instituições privadas, orienta-se pela racionalidade, descentralização, avaliação e terceirização, incluindo as políticas voltadas ao ensino superior.

Galleguillos e Catani (2011) apontam ainda que a reforma da educação superior é determinada por duas vertentes: a avaliação e a autonomia. A avaliação tem como objetivo verificar o rendimento de alunos e instituições, e seus resultados determinarão o repasse de recursos - a reestruturação acadêmica e, quanto à autonomia, refere-se prioritariamente às universidades, que passam a deter maior flexibilidade e a estar praticamente livres de controle dos sistemas de ensino.

A reforma educacional intensifica-se a partir da nova Lei de Diretrizes e Bases da Educação Nacional (LDB, 1996). Os indicadores utilizados para avaliação da educação superior relacionam-se à qualificação e à dedicação docente, à infraestrutura e às variáveis de processo, como métodos de ensino, organização curricular e gestão acadêmica. Para a avaliação institucional e a auto-avaliação, as variáveis de processo permitem uma avaliação qualitativa a partir de pareceres de especialistas, mas os parâmetros mais utilizados referem-se à produtividade, sendo pautados em eficiência e eficácia, a exemplo da avaliação dos recursos utilizados e sua relação com o número de alunos formados.

Segundo Valença e Menger (2012) a escola de hoje é uma instituição burguesa, nasceu revolucionária porque sua intenção era criar uma nova sociedade e um novo homem. A partir do século XIX, com este projeto de sociedade consolidado, a finalidade da escola muda de construtora de sociedade a perpetuadora destas condições sociais e econômicas. Desta forma, é inegável a ligação entre as mudanças na forma de produção econômica e a educação.

Valença e Menger (2012) dizem que a escola, como instituição que conhecemos, surge da necessidade dos burgueses e está inter-relacionada com a fábrica, portanto, cada mudança no modo de produção se reflete na educação. Observando por esse prisma, grande parte das teorias de Educação serviu para legitimar e apoiar as formas de produzir da sociedade ocidental, pelo menos nos últimos cinco séculos. Em função das exigências desta nova sociedade, passou-se a exigir também um novo tipo de trabalhador que fosse ativo e cada vez mais adaptável às mudanças tecnológicas, e para isso era necessária uma nova escola.

Denominada por Escola Nova, essa teoria surgida no Século XX, na década de 20 liderada por Anísio Teixeira, foi sucedida na década de 40 pela teoria Tecnicista ganhando espaço no Brasil em função da onda de industrialização. Um dos exemplos foi a criação do Sistema S, compreendido pelo Senai, Sesi, Senac, Sesc e Senar, que seria responsável pela qualificação dos trabalhadores da indústria, do comércio, da agricultura e da assistência social dos mesmos. Segundo Valença e Menger (2012) apud Saviani (1996), com o Regime Militar o tecnicismo foi consolidado como política pública para a área da educação. 
Com a sucessão de crises do capitalismo a partir da década de 1970, esse modo de produção passou por uma recomposição, chamada de Neoliberalismo. Segundo Duarte (2001), a extensão do Neoliberalismo na educação é o Construtivismo $^{1}$, em especial, as correntes derivadas do pensamento do suíço Jean Piaget. Duarte (2001) afirma que o Construtivismo é a retomada de pressupostos já abordados pela Escola Nova ${ }^{2}$ há algumas décadas, porém, dando outros significados a alguns conceitos e, desta forma, vincula-se ao pensamento pós-moderno. Entre os princípios desta abordagem pedagógica está a supervalorização do indivíduo. Assim, aquilo que o indivíduo aprende sozinho é superior ao que aprende por meio da transmissão. Outro ponto é que o método de construção do conhecimento é mais importante que o conhecimento já produzido socialmente.

Saviani (1996) sugeriu no início da década, a criação de uma teoria que buscasse superar o capitalismo e as condicionantes sociais. Para ele, a escola pode reproduzir a sociedade, mas mesmo o aspecto da reprodução não é mecânico, portanto, é contraditório.

Inicialmente, Saviani (1996) chama esta teoria de crítica dos conteúdos, depois de dialética e, por fim, de Pedagogia Histórica - Crítica. Saviani (1996) defende que a mudança social só será possível quando o proletário tiver acesso aos meios de produção e, dessa forma, altere o modo de produção, superando o capitalismo. Para isso, primeiramente é necessário dotar o proletariado dos mesmos conhecimentos que a burguesia detém. A educação deve ter como objetivo a formação do ser humano como um todo para que ao fim do período escolar as desigualdades de início não tenham sido ampliadas pela apropriação do saber historicamente produzido pela humanidade.

Severino (2000) trata da reflexão filosófico educacional sobre a condição da educação, como prática mediadora da existência histórica dos homens, explicitando seus desafios e compromissos diante da sua situação concreta no contexto social brasileiro da atualidade. O autor destaca os seguintes questionamentos: Qual a realidade histórica social encontrada no Brasil, neste atual momento? Como andam essas mediações nas quais cabe à educação investir? O país tem uma das mais altas concentrações de renda do mundo medida pelo índice $\mathrm{Gini}^{3}$, o que é um paradoxo,

\footnotetext{
1 Construtivismo: teoria criada pelo suíço Jean Piaget (1896-1980),define-se como a teoria do desenvolvimento do conhecimento em resultado de uma interação com o meio. Piaget procurou determinar os processos de construção do conhecimento desde as suas formas mais elementares até aos níveis superiores, nomeadamente o conhecimento científico.

2 Escola Nova: o grande nome do movimento na América foi o filósofo e pedagogo John Dewey (1859-1952). John Dewey, filósofo norte americano influenciou a elite brasileira com o movimento da Escola Nova. Para John Dewey a Educação, é uma necessidade social. Por causa dessa necessidade as pessoas devem ser aperfeiçoadas para que se afirme o prosseguimento social, assim sendo, possam dar prosseguimento às suas ideias e conhecimentos.

3 O Índice de Gini, criado pelo matemático italiano Conrado Gini, é um instrumento para medir o grau de concentração de renda em determinado grupo. Ele aponta a diferença entre os rendimentos dos mais pobres e dos mais ricos.
} 
pois o país enriqueceu nos últimos anos, porém não conseguiu transformar esta riqueza em maior expectativa de vida e em educação.

A saída, segundo Cavalcante (2013), para a elaboração de políticas públicas mais eficientes é conhecer e identificar quais são as necessidades de cada setor da economia e sugerir intervenções cirúrgicas, seja em educação ou inovação, por exemplo. "Quando conseguimos saber o que é importante para cada segmento, passamos a ter um portfólio de políticas com resultados mais efetivos num espaço de tempo menor" (CAVALCANTE, 2013, p. 9).

Gomes (2011) coloca que a qualificação da força de trabalho constitui um campo de estudos profícuo, porém, muito pouco explorado no Brasil, entretanto, desde a virada no ano 2000, no sistema produtivo, nos meios de comunicação e nas instituições representativas do capital, é voz corrente que o Brasil vive uma crise de mão de obra qualificada, sendo que algumas pesquisas não acadêmicas confirmam que o problema afeta, sobremaneira, a economia.

O autor conclui que durante muito tempo o problema da má qualidade da educação e da sua pouca abrangência foi negligenciado pelo Estado, também tendo uma baixa aderência por parte dos meios de comunicação. Ainda hoje ele é pouco debatido até mesmo por alguns segmentos da academia. Todavia, o mercado percebeu o quanto o problema o afeta, sendo que as empresas e os seus representantes vêm questionando o imobilismo governamental e cobrando das autoridades uma atitude consistente.

Em relação à legislação brasileira para a educação, com a LDB - Lei de Diretrizes e Bases - 9394/96, vieram também melhorias ao sistema educacional, principalmente no que se refere às políticas de inclusão social e projetos inéditos como os Parâmetros Curriculares (PCN's). Com essa Lei (9394/1996) se dá um processo de participação e representatividade no congresso de grupos reivindicatórios, através da discussão das necessidades educacionais brasileiras, resultantes de pesquisas censitárias e avaliações, que trouxeram a "realidade" das escolas brasileiras, mesmo que parcialmente, para o debate, sendo que, para objeto desta pesquisa destaca-se o art. $2^{\mathrm{o}}$ :

Art. $2^{-}$A educação, dever da família e do Estado, inspirada nos princípios de liberdade e nos ideais de solidariedade humana, tem por finalidade o pleno desenvolvimento do educando, seu preparo para o exercício da cidadania e sua qualificação para o trabalho. (BRASIL, LDB 1996)

Saviani (2005), afirma que na década de 90, a ideia da educação como o instrumento mais poderoso de crescimento econômico e, por consequência, de regeneração pessoal e de justiça social, se manifesta com toda sua força. 
Gomes (2013) apresenta dados extraídos da Pesquisa sobre Perspectivas Estruturais do Mercado de Trabalho na Indústria Brasileira 2020, Sistema Firjan, 2012, que consolidam a preocupação da classe empresarial:

- 94\% das empresas que enfrentam a falta de trabalhador qualificado têm dificuldade para encontrar operadores para a produção e afirmam que o problema prejudica o aumento da competitividade;

- $78 \%$ das empresas que enfrentam a falta de trabalhador qualificado têm a capacitação na própria empresa como uma das principais formas de lidar com o problema;

- 52\% das empresas industriais afirmam que a má qualidade da educação básica é uma das principais dificuldades que enfrentam para qualificar os trabalhadores;

- $69 \%$ das empresas consultadas enfrentam dificuldades com a falta de trabalhador qualificado. (SONDAGEM ESPECIAL, 2011, p. 1)

A pesquisa Perspectivas Estruturais do Mercado de Trabalho na Indústria Brasileira - 2020, realizada em Fevereiro 2012 pelo Sistema Firjan visou a identificar perspectivas do mercado de trabalho, no que tange à contratação e requisitos de formação educacional para carreiras em empresas industriais brasileiras, tendo como horizonte o ano de 2020; fornecer para estudantes, trabalhadores, empresas, instituições de ensino e governos um referencial estratégico para investimentos em educação e formação profissional.

\section{Momento atual do ensino superior}

De acordo com a pesquisa do Censo da Educação Superior feita pelo Inep (2012), o Brasil teve mais de 7 milhões de matrículas no ano passado. A pesquisa mostra que esse número representa aumento de 4,4\% no período 2011-2012. Enquanto o número de matrículas nas instituições públicas cresceu 7\%, o aumento na rede particular, responsável por 73\% do total, foi de 3,5\%. "Estamos em um sistema em forte expansão, com mais ingressantes que concluintes", observou o ministro da Educação, Aloizio Mercadante ${ }^{4}$, ao apresentar os dados gerais do Censo da Educação Superior (2012), durante entrevista coletiva concedida no MEC, em 2013. "Não é tarefa fácil assegurar qualidade da expansão de acordo com a demanda por vagas". Temos um compromisso no Ministério da Educação de assegurar a qualidade do ensino superior (MERCADANTE, 2013, p. 1).

4 Aloízio Mercadante - Ministro da Educação em entrevista dada à Assessoria de Comunicação do INEP - Instituto Nacional de Estudos e Pesquisas Educacionais Anísio Teixeira, em 17 de setembro de 2013. 
Considerando apenas a rede federal, o número de matrículas cresceu 5,3\% no mesmo período, superando a marca de 1,08 milhões de estudantes. As instituições federais representam 57,3\% da rede pública de educação superior. "Temos 7,2 milhões de estudantes do ensino superior e 7,1 milhões de inscritos no Enem, "Temos um volume equivalente de estudantes no Enem querendo entrar na universidade (MERCADANTE, 2013, p. 1).

Os 7.037.688 alunos matriculados em cursos de graduação no Brasil estão distribuídos em 31.866 cursos, oferecidos por 2.416 instituições - 304 públicas e 2.112 particulares. O total de estudantes que ingressaram no ensino superior em 2012 chegou a 2.747.089. Porém o número de concluintes foi apenas 1.050.413 (CENSO, 2012).

As universidades são responsáveis por mais de $54 \%$ das matrículas. As faculdades concentram 28,9\%; os centros universitários, 15,4\%; as instituições federais de educação tecnológica, 1,6\% (CENSO, 2012). No período 2011-2012, o número de ingressantes nas instituições de educação superior cresceu $17,1 \%$. Com taxa média de crescimento anual de $8,4 \%$ nos últimos dez anos, a rede federal registrou aumento no número de ingressantes superior a $124 \%$ entre 2002 e 2012. A rede já participa com mais de $60 \%$ dos ingressos nos cursos de graduação da rede pública (CENSO, 2012).

O Censo (2012) mostra também a expansão do número de matrículas nos cursos tecnológicos. Entre 2011 e 2012 , o total cresceu $8,5 \%$. Nos cursos de bacharelado, o aumento foi de $4,6 \%$ e nos de licenciatura, de $0,8 \%$. Com esse aumento, os cursos tecnológicos representam 13,5\% das matrículas na educação superior. Os de bacharelados e de licenciatura participam com $67,1 \%$ e $19,5 \%$, respectivamente. "O segmento que mais cresce em número de matrículas são os cursos tecnológicos. Isso tem muito a ver com o atual momento do Brasil, com o mercado de trabalho aquecido" (MERCADANTE, 2013).

Os dados mencionados acima consolidam a linha de pesquisa deste trabalho no sentido de que apesar da grande disponibilidade de instituições de ensino tanto pública quanto particular e, da grande quantidade de matrículas realizadas, muitos alunos abandonam as escolas sem concluir o curso consolidando o que apontam as pesquisas em relação à deficiência da oferta de mão de obra qualificada no mercado. Esses dados afetam o perfil do trabalhador prejudicando seu potencial de empregabilidade.

\section{Empregabilidade}

Empregabilidade é o conceito no qual se estabelece para os profissionais, empregados ou não, a obrigatória preocupação no sentido maior de se manterem permanentemente atualizados e empregáveis, diante das exigências de formação, em face das habilidades, especializações e talentos que o mercado de trabalho requer (CARVALHO, 2006).

Uma das grandes indagações atuais dos estudantes universitários é relativa ao potencial de oportunidades que a educação superior pode agregar ao desenvolvimento profissional, frente aos desafios das mudanças econômicas e 
sociais proporcionadas pela globalização, como a reestruturação produtiva e as consequentes alterações no mercado de trabalho no Brasil e no mundo (CARVALHO, 2006).

Não basta que o profissional tenha concluído um curso superior para assegurar a conquista de um emprego. $\mathrm{O}$ grau de exigibilidade cresceu muito, requerendo e esperando do profissional a demonstração de aptidões e conhecimentos de que as empresas necessitam na busca de novas alternativas organizacionais, bem como na solução de seus problemas, afirma Carvalho (2006).

De acordo com Chiavenato (2004), a crise do emprego transborda no Brasil e no mundo industrializado.

Existem vagas oferecidas que não são preenchidas devido ao "analfabetismo profissional" dos pretendentes. As profissões e qualificações estão em mudança. Quem não mudar junto com elas perde o bonde do emprego que passa. Isso vale para o chão de fábrica e para o comando das empresas. (CHIAVENATO, 2004, p. 379)

$\mathrm{O}$ autor apresenta uma pesquisa que a Catho $^{5}$ fez com 520 profissionais de média e alta gerência em São Paulo e Rio de Janeiro. Um em cada quatro deles estava desempregado - 54\% dos executivos desempregados não falam inglês e $41 \%$ não tiveram por conta própria nenhum curso de desenvolvimento ligado à sua profissão. 29\% não leram livro algum de interesse profissional nos últimos seis meses. Se o problema parece grave entre os executivos o que dizer então da grande massa de empregados em busca do emprego médio?

[..] com nova visão do mercado e do trabalho, houve uma profunda mudança no contrato de trabalho e, em consequência, a quebra do vínculo trabalhista, desestabilizando a relação entre empresa e empregado. Agora a peteca está na mão do funcionário. Depende de cada um a administração de sua carreira e das condições pessoais de sobrevivência e crescimento nessa luta incessante. É o autogerenciamento de carreira. A competitividade está cada vez mais exigindo de cada pessoa um incessante investimento em sua carreira e em sua preparação e qualificação profissional [...]. (CHIAVENATO, 2004, p. 110)

Dessa forma, é importante avançar na discussão sobre como as instituições de ensino superior estão implementando, do ponto de vista da qualidade, a dimensão da prática dos cursos que oferecem à sociedade de forma a garantir uma sólida relação entre teorias aprendidas e práticas organizacionais a serem vivenciadas pelos

5 Catho: site brasileiro de classificados de currículos e empregos. 
profissionais nas suas respectivas áreas. A universidade deveria assim, estar voltada para o aluno e para o mercado, entendendo suas expectativas e necessidades, de forma a oferecer uma estrutura de ensino adequada aos objetivos de seus acadêmicos e às necessidades do mercado de trabalho, assunto foco desta pesquisa.

Nesta perspectiva, considera-se importante conhecer a percepção de empregabilidade dos egressos das IES de São Mateus, ES, em 2013, visto que estão no mercado. Segundo Chiavenato (2004), empregabilidade significa a capacidade de conquistar e manter um emprego em uma organização.

Pessanha (1997) diz que as IES precisam se adequar ao novo cenário para atender às demandas emergentes, sem perder de vista o potencial de empregabilidade do trabalhador. A solução perpassa pela melhoria dos currículos e das políticas públicas, adequação da legislação trabalhista e conscientização de que as inovações tecnológicas devem estar a serviço do homem, pois a dignidade e a competência profissional fazem a diferença numa economia globalizada.

Uma nova civilização está se formando, a humanidade se depara com um salto importante à frente, a população vive a Terceira $\mathrm{Onda}^{6}$ antecedida respectivamente pela Primeira $\mathrm{Onda}^{7}$, momento da Revolução Agrícola e pela Segunda $\mathrm{Onda}^{8}$, considerada como o advento da civilização industrial, sendo sustentadas pelo trabalho braçal, porém a Terceira Onda se caracteriza pela qualificação da mão de obra.

Chiavenato (2004) confirma: O calcanhar de Aquiles das organizações - o seu principal ponto nefrálgico - é a qualidade das pessoas que nela trabalham. São as pessoas que lidam com a tecnologia, criam e utilizam processos de trabalho, compõem a estrutura organizacional, fazem produtos e serviços e atendem clientes. São as pessoas que proporcionam produtividade, qualidade e competitividade para as organizações.

\section{Resultados das pesquisas}

\subsection{Resultados da pesquisa quantitativa}

Essa pesquisa foi realizada com 154 egressos do ano 2013 das IES privadas de São Mateus, ES, perfazendo um percentual de $64 \%$ da amostragem, sendo contemplados alunos dos vários cursos oferecidos pelas instituições (Gráfico 1).

6 Terceira Onda - revolução técnico científica onde o novo modo de vida está baseado em fontes de energias renováveis, diferentes e alternativas. Ela apresenta uma nova era totalmente voltada à informação e ao conhecimento.

$7 \mathrm{Na}$ primeira onda ou sociedade agrária, onde a principal forma de capital era a terra. Foi uma forma de criar riqueza cultivando a terra e havia necessidade de um mínimo de noção sobre o plantio e o ânimo corporal para trabalhar.

8 Segunda onda, forma de criar riqueza, passou a ser a oficina industrial e a corretagem de bens. A fábrica passou a ser geradora de recursos econômicos e financeiros e a fundamental produtora de empregos. 
Gráfico 1. Total de egressos pesquisados

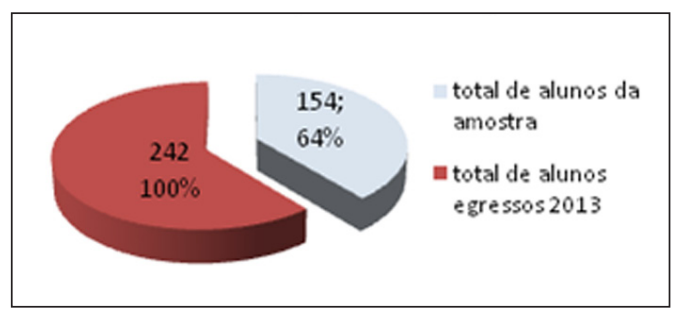

Gráfico 2. Faixa etária dos egressos

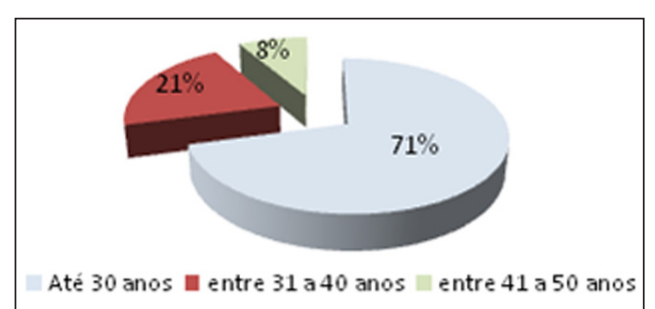

A faixa etária abrangeu em sua maioria, $71 \%$, alunos com menos de 30 anos, identificados como público alvo da pesquisa, seguido pelo percentual de $21 \%$ de alunos entre 31 e 40 anos e $8 \%$ para os acima de 41 anos. Os dados predominantes $(71 \%)$ consolidam as características apontadas na contextualização sobre o jovem apressado, dinâmico e em busca de resultados rápidos (Gráfico 2).

Em relação à procedência, 94\% dos egressos são urbanos, o que significa que a maioria vive a realidade tecnológica das cidades, sempre conectados e experimentando novas formas de comunicação (Gráfico 3).

Desses alunos, 49\% são filhos de pais concluintes do ensino fundamental, indicando claramente que a geração anterior não teve incentivos ou oportunidades de continuar seus estudos, interrompendo-os na segunda etapa. Essa predominância na região empata com a escolaridade materna que também identificou $48 \%$ dos pesquisados. A pesquisa mostra também que $35 \%$ dos pais e $30 \%$ das mães cursaram o ensino médio. Porém, apenas $10 \%$ das mães continuaram seus estudos, concluindo o ensino superior, seguidos de $7 \%$ dos pais com essa graduação (Gráfico 4).

Os Gráficos 4 e 5, identificam um forte gargalo na fragilidade da educação de base da população pesquisada, pode-se comprovar que tanto o pai quanto a mãe têm, predominantemente, somente o ensino fundamental, dado que prejudica a formação básica dos alunos pesquisados (Gráficos 4 e 5).
Gráfico 3. Procedência dos egressos

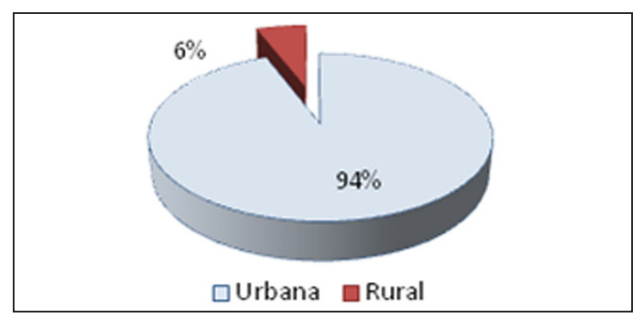

Gráfico 4. Escolaridade do pai

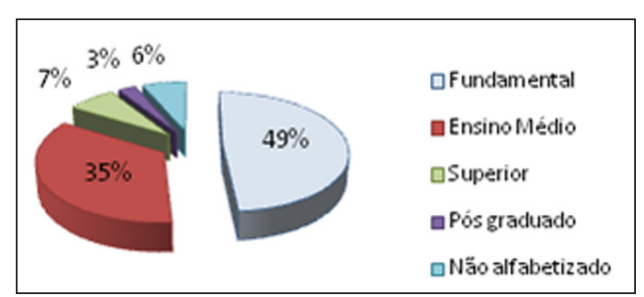

Gráfico 5. Escolaridade da mãe

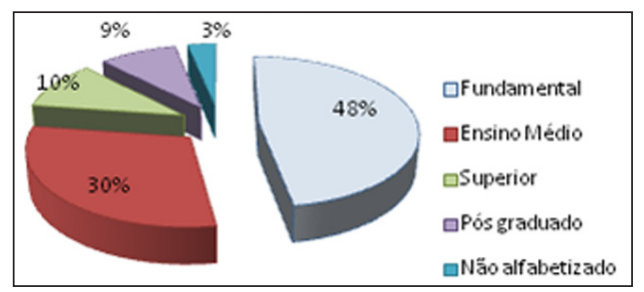


Gráfico 6. Egressos com bolsa de estudos

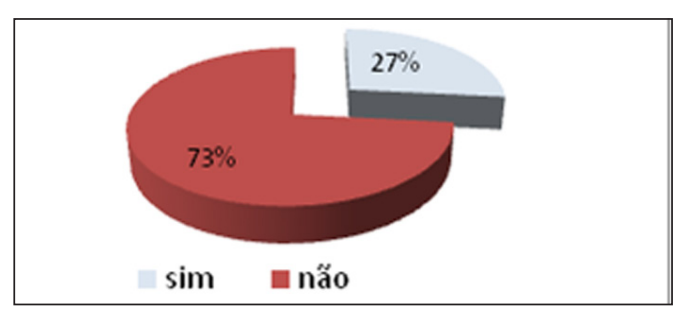

Gráfico 7. \% de alunos oriundos das escolas públicas e particulares

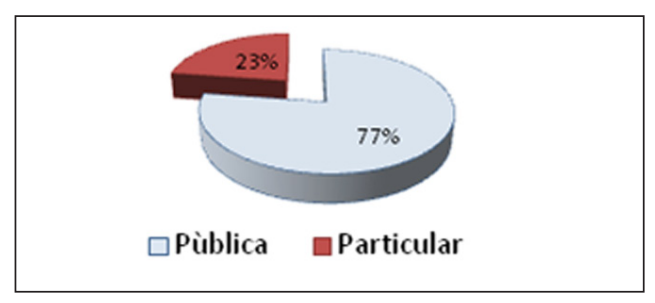

De acordo com o Gráfico 6 percebe-se que apenas $27 \%$ dos alunos possuem bolsa de estudo, o que evidencia uma característica preocupante, pois apenas os alunos com melhor desempenho nas escolas públicas são contemplados com este benefício (Gráfico 6).

Dos alunos, $77 \%$ vieram das escolas públicas locais e apenas $23 \%$ das escolas particulares (Gráfico 7).

Tendo em vista o percentual de $82 \%$ dos alunos que declaram não terem realizado nenhum outro idioma, além do ofertado pelas instituições públicas, pode ser justificado já que possivelmente os alunos oriundos das escolas públicas são de baixa renda. Esse gráfico mostra que os alunos não buscaram cursar outro idioma para melhorias de suas oportunidades profissionais, apenas $18 \%$ do público pesquisado apontou essa necessidade (Gráfico 8).

Dos egressos, 69\% disseram que a qualidade do ensino deixa a desejar declarando-a regular, o que significa que existem muitas possibilidades de melhorias no ensino recebido (Gráfico 9).

Observa-se que no Gráfico 10 pouca aderência com a realização de outros cursos, 56\% dos alunos não procuraram essa capacitação para que pudessem complementar sua educação (Gráfico 10).

Gráfico 8. Egressos que cursaram outro idioma

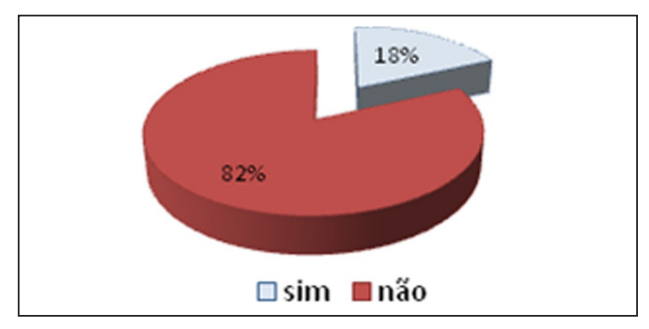

Gráfico 9. Qualidade da educação recebida

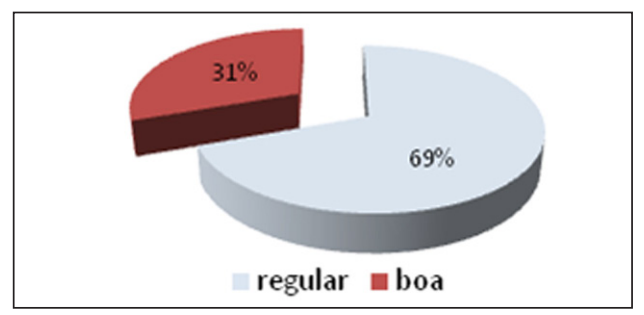

Gráfico 10. Egressos com cursos complementares

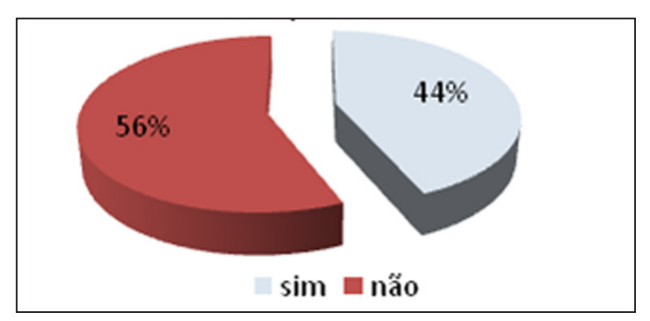


Os dados do Gráfico anterior (Gráfico 10) podem ser uma resposta à dificuldade com a empregabilidade dos alunos, pois, 68\% dos egressos responderam estar desempregados (Gráfico 11).

Além da identificação do alto percentual de dificuldade em conseguir emprego na cidade, em função da pouca oferta, $15 \%$ alegaram que os empregos ofertados proporcionam baixa remuneração e $20 \%$ responderam excesso de exigências acerca da qualificação para o cargo (Gráfico 12).

Dos alunos, 62\% consideram indispensável possuírem uma Pós-Graduação (Gráfico 13), e 71\% consideram também, que seria muito útil ter orientação profissional durante o período de graduação. A orientação profissional em um ambiente escolar, a partir da percepção fornecida verbalmente pelos egressos pesquisados, pareceu ser muito importante, pois, os alunos demonstraram insegurança na escolha da carreira que querem seguir (Gráfico 14).

Gráfico 11. Alunos desempregados

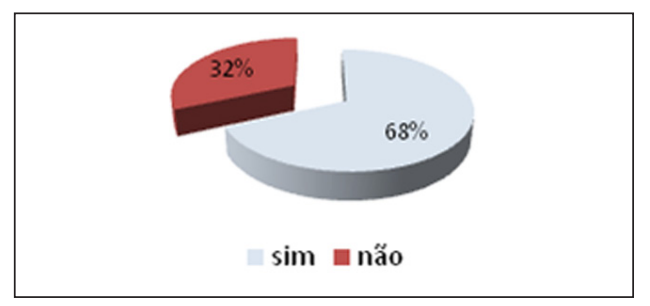

Gráfico 12. Dificuldade para conseguir emprego

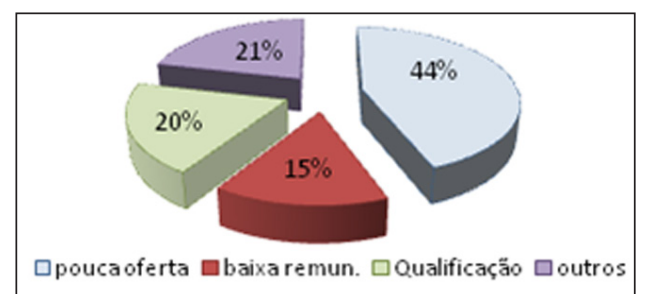

Gráfico 13. Importante fazer Pós-Graduação

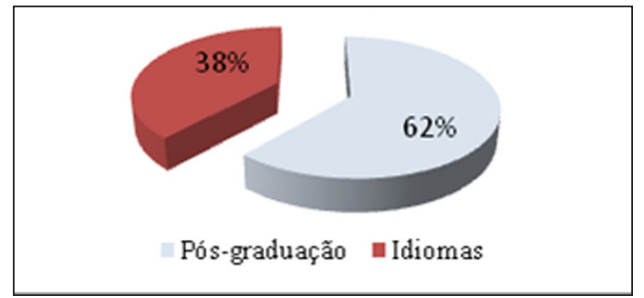

Gráfico 14. É útil ter orientação profissional

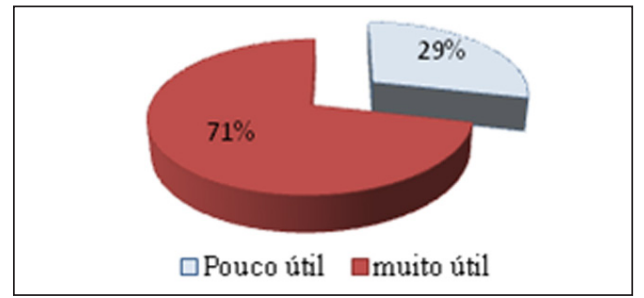




\subsection{Resultado da pesquisa qualitativa}

A pesquisa qualitativa selecionou três perguntas de relevância para a identificação dos fatores que contribuem para a captação e permanência do candidato na empresa. A mensuração dos dados produzidos a partir das respostas ao questionário, aplicado aos 31 gestores que se dispuseram a responder conclui-se que:

- A pergunta número 1 investigou sobre qual seria a maior dificuldade que encontram ao contratar novos funcionários. Os principais aspectos foram citados conforme se pode comprovar através dos dados apontados no Gráfico 15 que, mostra os percentuais de 57\% para a falta de qualificação, $17 \%$ para a falta de experiência, $14 \%$ para candidatos com dificuldades em aprender e, $11 \%$ com falta de foco na carreira que quer seguir.

Gráfico 15. Dificuldades na contratação de novos funcionários

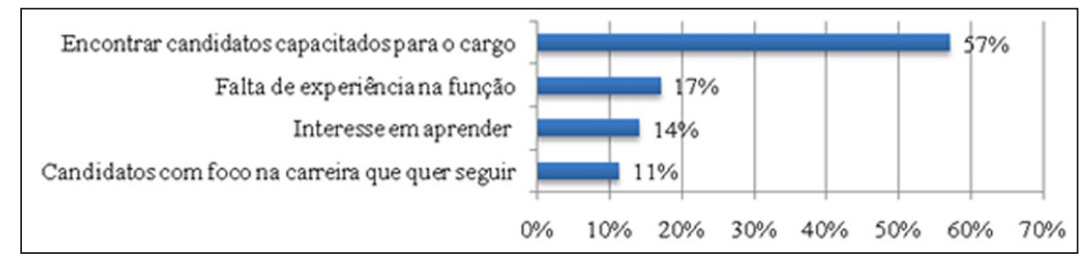

- A pergunta número 2 procurou filtrar o quesito de maior relevância no tocante às deficiências encontradas na oferta da mão de obra. O resultado apontou para a qualificação e falta de cultura predominando com $37 \%$ seguidos de conduta incorreta com $29 \%$, exigências em excesso com $20 \%$ e $14 \%$ para os candidatos sem foco (Gráfico 16).

Gráfico 16. Maiores relevâncias identificadas nas deficiências

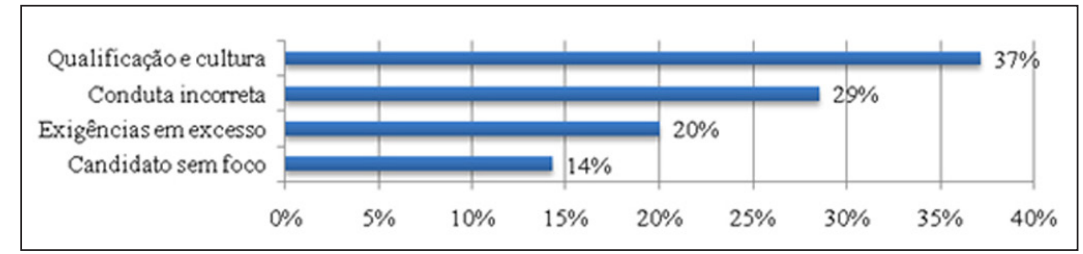


- Por fim, a pergunta no 3 da pesquisa procurou detectar o que seria relevante para melhorar a qualidade da oferta da mão de obra, objetivando alinhar a melhoria da qualidade entre a oferta e a demanda. Em relação às sugestões de melhoria, identificou-se prioritariamente a necessidade da implantação dos treinamentos dentro das organizações para suprir a falta de qualificação detectada, com um percentual de $46 \%$. Os gestores também apontaram que os alunos precisam de mais seriedade durante a vivência acadêmica, de realizar realmente cursos de autodesenvolvimento, ou seja, gerenciar as próprias carreiras com $11 \%$ empatando com a necessidade das empresas melhorarem as parcerias com as IES da região no sentido de se oferecer mais oportunidades de estudo para essa população (Gráfico 17).

Gráfico 17. Sugestões de melhorias para a qualificação

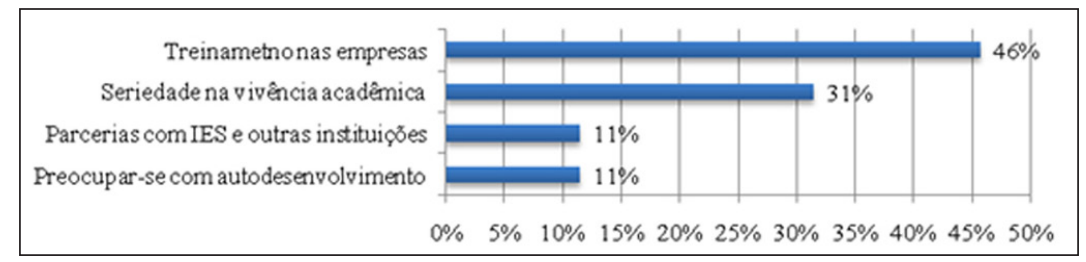

\section{Considerações finais}

O mercado de trabalho competitivo tem sido regido pelas diversas mudanças e transformações, pela inovação tecnológica e pela concorrência. Os profissionais concorrem com tantos outros por uma oportunidade de trabalho e as empresas concorrem com seus produtos, preços e exigências em relação à qualidade da mão de obra contratada.

Os jovens pesquisados possuem a faixa etária predominante de até 30 anos, com procedência urbana, o que significa que possuem maiores facilidades em termos de acessos às tecnologias mantendo-os sempre conectados e experimentando novas formas de comunicação. Esse dado consolida os comentários introdutórios dessa pesquisa.

Desse público alvo, 77\% são oriundos das escolas públicas do município e declararam não ter dificuldades em concluir o ensino médio. São filhos e filhas de pais com formação fundamental, o que de certa forma, aponta uma fragilidade em termos das exigências com a qualidade do ensino. Outro dado que identifica essa fragilidade é que a maioria não buscou ou não conseguiu bolsa de estudo, levando-nos a inferir que se pode detectar a baixa qualidade 
de ensino-aprendizagem, uma vez que para se conseguir bolsa de estudo o aluno necessita apresentar bom rendimento escolar. Outro aspecto a ser considerado é que sobram bolsas que os alunos oriundos das escolas públicas não conseguem em função da baixa pontuação no ENEM.

O mercado de trabalho, já há alguns anos, exige, para alguns cargos, o conhecimento de outro idioma e a pesquisa revelou que $82 \%$ dos alunos não cursaram outra língua, sendo este assunto tratado como um tema secundário para a formação profissional. Porém, $69 \%$ dos alunos pesquisados declararam que a qualidade do ensino formal poderia ser melhor em termos de conteúdo da grade curricular, pois esta não atende aos interesses dos alunos o que significa que existem muitas possibilidades de melhorias. Entretanto, apesar desta demanda educacional, $56 \%$ dos alunos não procuraram fazer outros cursos específicos para sua formação com vistas a complementar sua educação. Esses dados levam à inferência de que pode ser um caso de falta de orientação pedagógica, uma vez que $68 \%$ deles encontram-se desempregados e com dificuldades em conseguir emprego em função das exigências de qualificação, baixa remuneração e pouca oferta.

Os dados da pesquisa identificam que a qualificação dos candidatos está em defasagem em relação ao que o mercado exige. Em razão disso, o aprimoramento profissional através da Pós-Graduação é uma preocupação de grande relevância para os alunos. Acrescenta-se ainda, o percentual de $71 \%$ dos egressos que declararam ser muito útil a orientação profissional.

Em relação ao resultado da pesquisa de mercado profissional, os gestores pesquisados apontaram predominantemente para a falta de qualificação consolidando a acareação entre as duas pesquisas. Esse se constituiu como o maior entrave para as contratações da mão de obra local. Outros aspectos também relevantes foram apontados, como por exemplo, a falta de experiência na função, expectativa de ganhos mais altos, dificuldades comportamentais e candidatos sem foco naquilo que realmente desejam em termos profissionais. As empresas precisam ter a pessoa certa na função certa para garantir maior produtividade. A falta de foco produz inconsistência na contratação, razão esta, que demanda a qualificação do candidato como uma exigência prioritária. $\mathrm{O}$ futuro será de grandes mudanças, afirmam os entrevistados. Os profissionais melhores preparados terão maiores chances de inserção ao mercado de trabalho. Os candidatos precisam possuir diferenciais, pois, somente a formação acadêmica não é mais suficiente para o profissional do futuro. Quem tem experiência profissional e oferece outras características pessoais tais como postura, ética e disposição para o aprendizado, reúne mais chances de conquistar seu espaço no mundo corporativo.

As competências exigidas pelo mercado de trabalho apontam também para as atitudes que essas pessoas terão diante das oportunidades profissionais. Atualmente o mercado está em transformação, e o sucesso dos profissionais não depende só da formação e sim de todo contexto de desenvolvimento que esta pessoa teve ao longo de sua carreira profissional. 
Dessa forma, os resultados apontam para a necessidade de se criar condições acadêmicas no sentido de se capacitar o aluno com foco no desenvolvimento profissional quer seja dando maior ênfase a algumas disciplinas que se ajuste a essas necessidades, tendo um núcleo de orientação profissional que promova cursos e oficinas de pequena duração, com foco no desenvolvimento desse aprendizado.

Em relação ao que as empresas propuseram como solução para se minimizar essa defasagem coloca-se, prioritariamente, as seguintes sugestões: Fornecer treinamentos para os novos contratados de acordo com sua área de atuação; fazer campanhas internas para incentivá-los a se manterem atualizados com as novidades do mercado; oferecer convênios e parcerias com as IES da região para que o funcionário continue sua capacitação; destacar a importância da seriedade durante a vivência nas faculdades, incentivar a realização do aprendizado técnico para melhoria da qualificação específica sendo que, essa defasagem é um dos principais gargalos identificados na pesquisa acadêmica, pois, o pouco aproveitamento dos conteúdos estudados se apresenta muito marcado no desenvolvimento cultural desses alunos; direcionar os treinamentos no sentido de fortalecer as áreas que sofrem maiores impactos: cálculos financeiros, comunicação e relacionamentos interpessoais; desenvolver programas internos atrativos para a retenção de talentos; valorização da mão de obra existente com remunerações mais atrativas; fazer parcerias com Senai, Sesi, Sebrae e outras entidades que capacitam tecnicamente.

A maioria dos discentes tem consciência de que o mercado de trabalho está cada vez mais exigente e em constantes mudanças. Sabem que o universo acadêmico oferece transformações em suas vidas que jamais voltam a serem as mesmas. Sabe também, que as dificuldades financeiras das famílias fazem parte da realidade de muitos acadêmicos, o que faz com que muitos desistam de estudar ao surgirem os primeiros obstáculos. Entretanto, todos os alunos entrevistados garantem que apenas a formação tradicional não é mais suficiente para atender às demandas de um mercado exigente e, o que valerá no futuro será o diferencial que esses profissionais puderem oferecer.

\section{Referências}

ABNT. Parte I - Diretrizes para Apresentação de Dissertações e Teses da US. [Documento eletrônico\}. 2. ed. São Paulo: Universidade de São Paulo, 2009.

BRASIL. Lei no 9.131 de 24 de novembro de 1995. Altera dispositivos da Lei no 4.024, de 20 de dezembro de 1961, e dá outras providências. Disponível em: <http://www.pedagogiaemfoco.pro.br/19131_95.htm>. Acesso em: 20 out. 2013.

BRASIL Lei no 9.394 de 20 de dezembro de 1996. Lei das Diretrizes e Bases da Educação. Estabelece as diretrizes e bases da educação nacional. Diário Oficial da União, Brasília, DF, 23 dezembro de 1996. Seção I. Disponível em: <http://www.planalto.gov.br/ccivil_03/ LEIS/L9394.htm\#art92>. Acesso em: 08 set. 2013. 
BRESSER, Pereira, Luiz Carlos. Crise econômica e reforma do Estado no Brasil: para uma nova interpretação da América Latina. São Paulo, 1996.

CAVALCANTE, Luiz Ricardo. O desafio de ampliar a produtividade. Revista IPEA - Desafio do Desenvolvimento, ano 10, n. 78, 2013. Disponível em: $<$ http://www.ipea.gov.br/desafios/index.php?option=com_content\&view=article\&id=2973:catid=28\&Itemid=23>. Acesso em: 20 jan. 2013.

CARVALHO, Pedro Carlos de. Empregabilidade - a competência necessária para o sucesso no novo milênio. Campinas: Alínea, 2006. CATHO ONLINE. [Pesquisa] A contratação, demissão e a carreira dos executivos brasileiros. Ed. 2011. Disponível em: < http:// img.catho.com.br/site/pesquisas/pdf/pesquisa-dos-executivos-2011.pdf>. Acesso em: 25 jul. 2012.

CENSO. Censo da Educação Superior: primeiros resultados. 2012.

CHIAVENATO, Idalberto. Gestão de pessoas: o novo papel dos recursos humanos nas organizações. Rio de Janeiro: Campus, 2004.

CHIAVENATO, Idalberto. Talento e empregabilidade. 2004. Disponível em: $<$ http://www2.delta-search.com/?q=CHIAVENATO+\% 2B+TALENTO+E+EMPREGABILIDADE\&babsrc $=\mathrm{NT} \_s s \& s=w e b \& r l z=0 \& a s=0 \& a c=0>$. Acesso em: 15 set. 2013 .

DUARTE, N. As pedagogias do "aprender a aprender" e algumas ilusões da assim chamada sociedade do conhecimento. Revista Brasileira de Educação, Belo Horizonte, n. 18, p. 35-40, 2001 a.

DRUCKER, Peter Ferdinand. O melhor de Peter F. Drucker. Tradução de Arlete Simille Marques. São Paulo: Nobel, 2001.

FONSECA, Renato. O desafio da qualificação da mão de obra. Informativo Empresas Randon, Fenatran/Caxias do Sul, n. 113, bloco Empregabilidade, p. 8, dez. 2011.

FLECK, Carolina Frido. A tríade ensino-pesquisa-extensão e os vetores para o desenvolvimento regional (Ensaio). In: Revista Brasileira de Gestão e Desenvolvimento Regional, v. 7, n. 3, p. 270-298, set.-dez. 2011.

GALleguillos, Tatiana Gabriela Bressea; CATANI, Afrânio Mendes. Avaliação da Educação Superior no Brasil. In: Revista Educação e Pesquisa Scielo, Universidade Nove de Julho, SP,. v. 37, n..4, São Paulo, dez. 2011. Disponível em: <http://www.scielo. br/scielo.php?script=sci_arttext\&pid=S1517-97022011000400011>. Acesso em: 19 out. 2013.

GOMES, Cândido. Educação para o trabalho. Palestra apresentada na Universidade Católica de Brasília, PUC-DF. Brasilia, 15 de agosto de 2013 .

GOMES, Carlos Antonio. Uma crise do capital humano na economia brasileira. In: Revista PG\&C - Perspectiva em Gestão do Conhecimento, João Pessoa, v. 3, n. 1, p. 192-209, jan.-jun. 2011. Disponível em: <http://periodicos.ufpb.br/ojs2/index.php/pgc/article/ view/13825/9330>. Acesso em: 19 out. 2013.

INSTITUTO Nacional de Estudos e Pesquisas Educacionais “Anísio Teixeira” - INEP. Thesaurus Brasileiro da Educação. 2009. Disponível em: <http://portal.inep.gov.br/pesquisa-thesaurus>. Acesso em: 25 out. 2013.

MARCONI, M. D. A.; LAKATOS, E. M. Técnicas de pesquisa: planejamento e execução de pesquisas, amostragens e técnicas de pesquisas, elaboração, análise e interpretação de dados. 3. ed. São Paulo: Atlas, 1996.

MARCONI, M. D. A.; LAKATOS, E. M. Fundamentos de metodologia científica. 5. ed. São Paulo: Atlas, 2003. 
MEC/INEP. Instituto Nacional de Estudos e Pesquisas Educacionais “Anísio Teixeira”. Portaria INEP no 63, de 3 de junho de 2004. Designa membros da Comissão Assessora da Área de Enfermagem. Diário Oficial da União, n. 108, seção 2, p. 13, 7 jun. $2004 a$.

MERCADANTE, Aloízio. Entrevista dada ao INEP - Instituto Nacional de Estudos e Pesquisas Educacionais "Anísio Teixeira", Assessoria de Comunicação Social em 19 set. 2013. Disponível em: <http://portal.inep.gov.br/visualizar/-/asset_publisher/6AhJ/ content/brasil-teve-mais-de-7-milhoes-de-matriculas-no-ano-passado?redirect=http\%3a\%2f\%2fportal.inep.gov.br\%2f $>$. Acesso em: 22 set. 2013.

PESSANHA, João Batista. Qualificação profissional. In: Revista Vértices, Instituto Federal de Educação, Ciência e Tecnologia Fluminense. Disponível em: <http://link.periodicos.capes.gov.br/sfxlcl41?ctx_ver=Z39.88->. Acesso em: 26 out. 2013.

RELATÓRIO de Desenvolvimento Humano 2013 - RDH. Índice de Desenvolvimento Humano. Disponível em: <http:/hdr.undp.org/ en/media/HDR2013\%20Report\%20Portuguese.pdf>. Acesso em: 25 out. 2013.

RIBEIRO, Darcy. Projeto Darcy Ribeiro. Apresentado ao Ministério da Educação com propostas para transformar a LDB nacional. Disponível em: <http://www.senado.gov.br/senado/grandesMomentos/darcy.shtm>. Acesso em: 19 out. 2013.

SAVIANI, Demerval. Escola e democracia. 30. ed. Campinas, SP: Autores Associados, 1996.

SAVIANI, Demerval. As concepções pedagógicas na história da educação brasileira. Texto elaborado no âmbito do projeto de pesquisa "O espaço acadêmico da pedagogia no Brasil", financiado pelo CNPq. Campinas, 2005. Disponível em: <http://www.histedbr.fae. unicamp.br/navegando/artigos_pdf/Dermeval_Saviani_artigo.pdf>. Acesso em: 08 set. 2013.

SAVIANI, Demerval. História das ideias pedagógicas no Brasil. Campinas, SP: Autores Associados, 2008.

\section{Endereço para correspondência:}

Maria Nilda Bissaro

Rua Prof. Isaura Santos, 469 - Boa Vista

29931-400 São Mateus, ES, Brasil

<nilbissaro@terra.com.br>

Recebido em: julho/2014

Aceito em: dezembro/2014 